\title{
MEK inhibitor CS3006
}

National Cancer Institute

\section{Source}

National Cancer Institute. MEK inhibitor CS3006. NCI Thesaurus. Code C155971.

An orally bioavailable small-molecule inhibitor of mitogen-activated protein kinase kinase (MAP2K; MAPKK; MEK), with potential antineoplastic activity. Upon oral administration, MEK inhibitor CS3006 specifically targets, binds to and inhibits the catalytic activity of MEK, thereby inhibiting the activation of MEK-dependent effector proteins including extracellular signal-regulated kinase (ERK) and inhibits the proliferation of tumor cells in which the RAS/RAF/MEK/ERK signaling pathway is overactivated. The threonine/tyrosine protein kinase MEK plays a key role in the RAS/RAF/MEK/ERK signaling pathway, which is frequently upregulated in a variety of tumor cell types. The RAS/RAF/MEK/ERK pathway regulates key cellular activities including cell growth, proliferation, survival, differentiation and apoptosis. 